\title{
Effect of acetylcysteine solution combined with fiberoptic bronchoscopy alveolar lavage in elderly patients with severe ventilator-associated pneumonia
}

\author{
Ju Guo ${ }^{1}$, Ping Wang ${ }^{2}$, Xiaoyu Ma ${ }^{2 *}$ \\ ${ }^{1}$ The First Affiliated Hospital of Xinjiang Medical University, Department of Critical Care Medicine,137 Liyushan South Road, \\ Urumqi, Xinjiang 830054, ${ }^{2}$ The Fourth Hospital of Shijiazhuang, Department of Anesthesiology. 206 Zhongshan East Road, \\ Shijiazhuang 050000, China
}

*For correspondence: Email: ganyuetan1857@163.com

Sent for review: 30 January 2021

Revised accepted: 28 April 2021

\begin{abstract}
Purpose: To explore the effect of acetylcysteine solution combined with fiberoptic bronchoscopy alveolar lavage in elderly patients with severe ventilator-associated pneumonia (VAP).

Methods: A total of 120 elderly patients with severe VAP admitted to Department of Critical Care Medicine, the First Affiliated Hospital of Xinjiang Medical University in the past two years were selected for this study. They were randomized into groups $A$ and B. Group B underwent fiberoptic bronchoscopy alveolar lavage for 7 days, group A received acetylcysteine solution plus. Clinical pulmonary infection score (CPIS), respiratory mechanics changes, blood gas levels, inflammatory factor levels, antibiotic use time and mechanical ventilation time were compared.

Results: Compared to group B, group A witnessed a lower CPIS, an evidently superior dynamic lung compliance (Cdyn), and worse for other respiratory mechanics indices $(p<0.001)$. After treatment, the partial pressure of blood oxygen $\left(\mathrm{PaO}_{2}\right)$ and oxygenation index $\left(\mathrm{PaO}_{2} / \mathrm{FiO}_{2}\right)$ saw a surge; the partial pressure of carbon dioxide $\left(\mathrm{PaCO}_{2}\right)$ tapered off, and the levels of inflammatory factors witnessed a slump in group $A$ than compared with those for group $B(p<0.001)$. A shorter antibiotic use time and mechanical ventilation time was observed in group $A$ compared with group $B(p<0.001)$.

Conclusion: Acetylcysteine solution combined with fiberoptic bronchoscopy alveolar lavage yields a promising outcome in notably ameliorating CPIS, respiratory mechanics indicators and blood gas levels, driving down the level of inflammatory factors and diminishing treatment time in elderly patients with severe VAP.
\end{abstract}

Keywords: Acetylcysteine, Fibrobronchoscope, Alveolar lavage, Pneumonia

\begin{abstract}
This is an Open Access article that uses a funding model which does not charge readers or their institutions for access and distributed under the terms of the Creative Commons Attribution License (http://creativecommons.org/licenses/by/4.0) and the Budapest Open Access Initiative (http://www.budapestopenaccessinitiative.org/read), which permit unrestricted use, distribution, and reproduction in any medium, provided the original work is properly credited.

Tropical Journal of Pharmaceutical Research is indexed by Science Citation Index (SciSearch), Scopus, International Pharmaceutical Abstract, Chemical Abstracts, Embase, Index Copernicus, EBSCO, African Index Medicus, JournalSeek, Journal Citation Reports/Science Edition, Directory of Open Access Journals (DOAJ), African Journal Online, Bioline International, Open-J-Gate and Pharmacy Abstracts
\end{abstract}

\section{INTRODUCTION}

Ventilator-associated pneumonia (VAP), usually caused by mechanical ventilation and with a high morbidity in the elderly population, not only leads to weaning failure, but also strikingly increases the mortality of the patients, which inflicts damage on patients' quality of life [1-3]. At present, the primary purpose of VAP treatment in clinical practice is to bring down the infection 
degree of patients and optimize their respiratory function. Antibiotics, the long appreciated and most preferred drugs for VAP notwithstanding, are drastically undermined by multidrug-resistant bacteria. Consequently, indispensable as it is, the exploration of additional treatments requires further in-depth research in the field. To date, bronchofiberscope alveolar lavage has been widely used in the treatment of VAP, which can effectively suck out the pulmonary secretions of patients and improve the late application effect of antibiotics [4-6]. In addition, acetylcysteine solution can fully liquefy sputum and make it easier to be discharged, which theoretically confirms a good auxiliary effect on bronchoalveolar lavage. However, there were few experiments to study the combination of acetylcysteine solution and bronchoalveolar lavage. Based on this, 120 patients with related diseases treated in recent two years were selected as research samples to explore the application effect of the combination of acetylcysteine solution and bronchoalveolar lavage in elderly patients with severe VAP.

\section{METHODS}

\section{Patient profile}

A total of 120 elderly patients with severe VAP admitted to Department of Critical Care Medicine, the First Affiliated Hospital of Xinjiang Medical University in recent two years were selected and randomized to group $A$ and group B. The general data were comparable $(p>0.05)$, as displayed in Table 1 . The study followed International Compilation of Human Research Standards [7] and was approved by Medical Ethics Committee of the First Affiliated Hospital of Xinjiang Medical University, China (approval no. 20181215-01).

Table 1: General patient profile

\begin{tabular}{|c|c|c|c|c|c|}
\hline Group & Number of cases $(n=120)$ & Group A $(n=60)$ & Group B $(n=60)$ & $t / X^{2}$ & $P$-value \\
\hline Gender & & & & 0.031 & 0.861 \\
\hline Male & 65 & 32 & 33 & & \\
\hline Female & 55 & 28 & 27 & & \\
\hline Age (years old) & 120 & & & 0.142 & 0.887 \\
\hline Range & & $60-84$ & $61-84$ & & \\
\hline Mean age & & $65.1 \pm 7.8$ & $65.3 \pm 6.9$ & & \\
\hline Category & & & & 0.044 & 0.833 \\
\hline Early onset & 45 & 22 & 23 & & \\
\hline Late onset & 75 & 38 & 37 & & \\
\hline APACHE II & 120 & $20.0 \pm 3.0$ & $20.1 \pm 2.9$ & 0.178 & 0.859 \\
\hline Medical history & & & & 0.222 & 0.637 \\
\hline Diabetes & 36 & 17 & 19 & & \\
\hline Hypertension & 68 & 33 & 35 & & \\
\hline
\end{tabular}

\section{Inclusion criteria}

(1) Patients with VAP; (2) Patients with mechanical ventilation $\geq 48 \mathrm{~h}$; (3) Patients with abnormal signs and the trachea accompanied by secretions; (4) Patients or their families had full knowledge of the research process and signed the informed consent.

\section{Exclusion criteria}

(1) Patients with other organ diseases or lung diseases; (2) Patients with mental problems.

\section{Treatments}

All patients were treated with routine VAP, including bronchoalveolar lavage with fiberoptic bronchoscope. The steps were as follows: (1) In the pine position, patients were given local anesthesia with lidocaine (Tongfang Pharmaceutical Group Co., Ltd., Guo Yao Zhun Zi H20063466). (2) The fiberoptic bronchoscope (Shanghai Hongmai Medical Equipment Co., Ltd., Hu Xie Zhu Zhun 2016220684) was used to suck out secretions, which were then sent for inspection and culture; (3) Normal saline was used to irrigate the diseased parts of patients repeatedly, and was stopped after the aspirate was clarified [8-11]. Bronchoscopic alveolar lavage was performed once a day for 1 week.

Patients in group A were treated with acetylcysteine solution (ZAMBON ITALIA S.R.L, $\mathrm{H} 20150548$ ) by atomization inhalation, each time with $2 \mathrm{ml}$, twice a day, for 1 week continuously [12-15]. 


\section{Evaluation criteria for curative effect}

The evaluation criteria of curative effect in this study included CPIS, respiratory mechanics change, blood gas level, inflammatory factor level, antibiotic use time and mechanical ventilation time: (1) CPIS: the data were recorded before treatment, 1 day, 3 days and 7 days postoperatively. The lower the score, the better the patient's condition. (2) Respiratory mechanics changes: the plateau pressure (Pplat), Cdyn, airway resistance (RAW) and work of breathing (WOB); (3) Blood gas level: $\mathrm{PaO}_{2}$, $\mathrm{PaCO}_{2}$ and $\mathrm{PaO}_{2} / \mathrm{FiO}_{2} ;$ (4) Levels of inflammatory factors: IL-8, CRP and PCT; (5) Antibiotic use time and mechanical ventilation time: day was taken as the unit, and the data of two groups were compared.

\section{Statistical analysis}

SPSS20.0 was used for the data processing. Graphs were built using GraphPad Prism 7 (San Diego, USA). $\mathrm{X}^{2}$ test and $t$ test were performed.

\section{RESULTS}

\section{CPIS}

The CPIS for patients in group A were $9.2 \pm 1.6$, $7.2 \pm 1.5,5.1 \pm 1.2$ and $4.3 \pm 1.2$ days $0,1,3$ and 7 , respectively, while for patients in group $B$ CPIS was $9.3 \pm 1.5,8.5 \pm 1.4,7.9 \pm 1.1$ and 6.8 \pm 1.0 on days $0,1,3$ and 7 , respectively $(p<$ $0.001)$. After treatment, group A showed lower CPIS values than group B $(p<0.001)$, as shown in Figure 1.

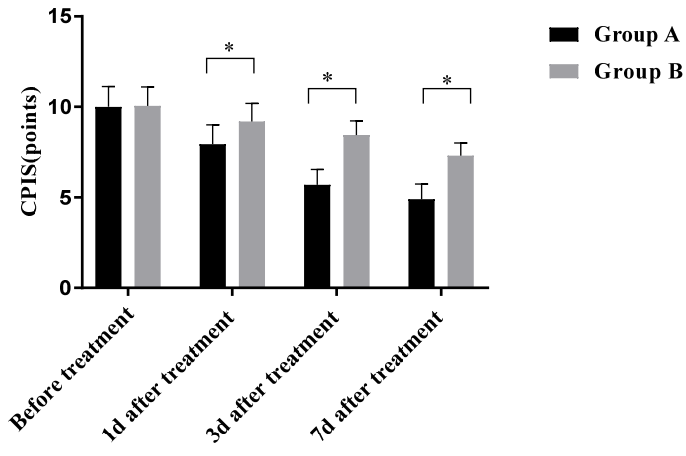

Figure 1: CPIS in patients (mean $\pm \mathrm{SD}$ ) on days 0,1 , 3 and 7

\section{Respiratory mechanics}

After treatment, the two groups both yielded favorable results in terms of the respiratory mechanics indexes $(p<0.001)$. In comparison with group $B$, the higher results of $C$ dyn but lower of other indexes in group A were obtained $(p<$ 0.001 ), as shown in Table 2.

\section{Blood gas level}

By contrast to group $\mathrm{B}$, group $\mathrm{A}$ garnered a rosy outcome with better $\mathrm{PaO}_{2}$, lower $\mathrm{PaCO}_{2}$ level and higher $\mathrm{PaO}_{2} / \mathrm{FiO}_{2}(p<0.001)$, as shown in Figure 2. $\mathrm{PaO}_{2}$ and $\mathrm{PaCO}_{2}$ in group $\mathrm{A}$ after treatment were $90.3 \pm 3.4$ and $36.3 \pm 2.7 \mathrm{mmHg}$, while for group B after treatment while the indices were $82.1 \pm 3.0$ and $45.1 \pm 3.1) \mathrm{mmHg}$, respectively $(p<0.001)$.

Table 2: Changes in respiratory dynamics of patients (mean \pm SD)

\begin{tabular}{|c|c|c|c|c|c|}
\hline Group & Time & Group A & Group B & $t$ & $P$-value \\
\hline Pplat & Before treatment & $28.0 \pm 4.2$ & $27.9 \pm 4.1$ & 0.126 & 0.900 \\
\hline \multirow[t]{3}{*}{$\left(\mathrm{cmH}_{2} \mathrm{O}\right)$} & After treatment & $11.0 \pm 2.1$ & $13.4 \pm 2.3$ & 5.715 & 0.000 \\
\hline & $\mathrm{t}$ & 26.849 & 22.875 & & \\
\hline & P-value & 0.000 & 0.000 & & \\
\hline Cdyn & Before treatment & $28.1 \pm 4.9$ & $28.2 \pm 4.7$ & 0.109 & 0.913 \\
\hline \multirow{3}{*}{$\left(\mathrm{mL} / \mathrm{cmH}_{2} \mathrm{O}\right)$} & After treatment & $46.7 \pm 5.0$ & $40.1 \pm 4.5$ & 7.276 & 0.000 \\
\hline & $\mathrm{t}$ & 19.704 & 13.563 & & \\
\hline & P-value & 0.000 & 0.000 & & \\
\hline$R A W$ & Before treatment & $16.9 \pm 3.0$ & $16.8 \pm 3.1$ & 0.172 & 0.864 \\
\hline \multirow[t]{3}{*}{$\left(\mathrm{cmH}_{2} \mathrm{O} \cdot \mathrm{L}^{-1} \cdot \mathrm{s}^{-1}\right)$} & After treatment & $10.1 \pm 2.1$ & $13.5 \pm 2.3$ & 8.096 & 0.000 \\
\hline & $\mathrm{t}$ & 13.771 & 6.340 & & \\
\hline & $\mathbf{P}$-value & 0.000 & 0.000 & & \\
\hline WOB & Before treatment & $0.9 \pm 0.2$ & $0.9 \pm 0.1$ & 0.000 & 1.000 \\
\hline \multirow[t]{3}{*}{$(J / L)$} & After treatment & $0.4 \pm 0.1$ & $0.6 \pm 0.2$ & 6.633 & 0.000 \\
\hline & $\mathrm{t}$ & 16.583 & 9.950 & & \\
\hline & $\mathbf{P}$-value & 0.000 & 0.000 & & \\
\hline
\end{tabular}


Table 3: Inflammatory factors in patients (mean \pm SD)

\begin{tabular}{|c|c|c|c|c|c|}
\hline Group & Time & Group A & Group B & $\mathbf{t}$ & $P$-value \\
\hline IL-8 & Before treatment & $149.0 \pm 11.6$ & $148.9 \pm 11.5$ & 0.045 & 0.964 \\
\hline (pg/ml) & $\begin{array}{l}\text { After treatment } \\
t\end{array}$ & $\begin{array}{c}100.5 \pm 8.5 \\
25.011 \\
0.000\end{array}$ & $\begin{array}{c}140.6 \pm 10.8 \\
3.902 \\
0.000\end{array}$ & 21.638 & 0.000 \\
\hline CRP & Before treatment & $78.5 \pm 9.3$ & $79.0 \pm 8.6$ & 0.293 & 0.770 \\
\hline (mg/L) & $\begin{array}{l}\text { After treatment } \\
\mathrm{t} \\
P \text {-value }\end{array}$ & $\begin{array}{c}37.1 \pm 6.0 \\
27.742 \\
0.000\end{array}$ & $\begin{array}{c}67.2 \pm 8.2 \\
7.365 \\
0.000\end{array}$ & 21.970 & 0.000 \\
\hline $\begin{array}{l}P C T \\
(n g / L)\end{array}$ & $\begin{array}{l}\text { Before treatment } \\
\text { After treatment } \\
\mathrm{t} \\
P \text {-value }\end{array}$ & $\begin{array}{c}27.1 \pm 4.1 \\
15.3 \pm 2.4 \\
18.420 \\
0.000\end{array}$ & $\begin{array}{c}27.2 \pm 4.0 \\
21.8 \pm 3.1 \\
7.914 \\
0.000\end{array}$ & $\begin{array}{l}0.129 \\
12.296\end{array}$ & $\begin{array}{l}0.897 \\
0.000\end{array}$ \\
\hline
\end{tabular}

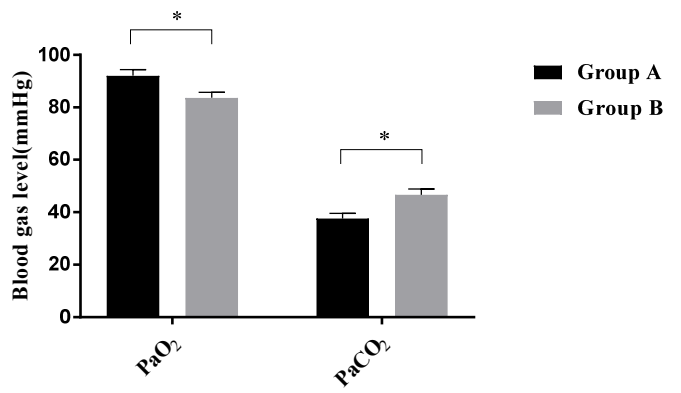

Figure 2: Blood gas levels of patients (mean \pm SD). Note: Partial pressure of oxygen $=\mathrm{PaO}_{2}$ and partial pressure of carbon dioxide $=\mathrm{PaCO}_{2}$

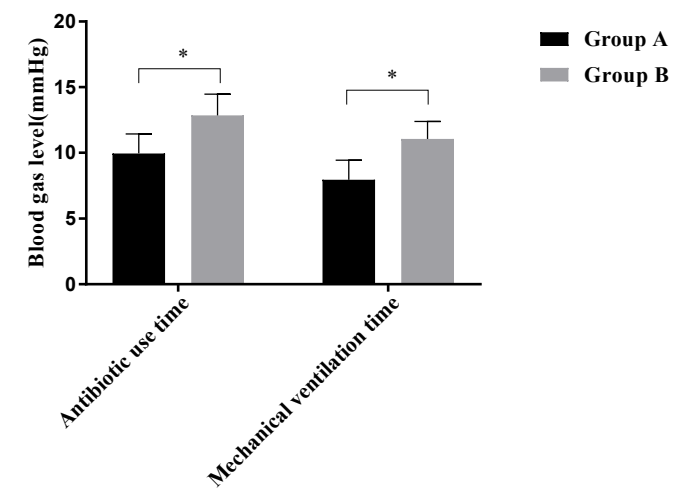

Figure 3: Comparison of antibiotic use time and mechanical ventilation time of patients (mean \pm SD)

\section{Inflammatory factor level}

After treatment, strong evidence of lower levels of inflammatory factors in group $A$ when compared with group $B$ was observed in Table 3 $(p<0.001)$.

\section{Antibiotic use time and mechanical ventilation time}

Compared to group $B$, patients in group $A$ enjoyed a shorter antibiotic use time and mechanical ventilation time $(p<0.001)$, as shown in Figure 3. Antibiotic use time and mechanical ventilation time in group $A$ were $8.9 \pm$ 2.1 and $6.9 \pm 2.1$ days, while for group $B$ the corresponding values were $11.7 \pm 2.3$ and $10.1 \pm$ 1.9 days, respectively; ${ }^{*} p<0.001$.

\section{DISCUSSION}

As one of the serious complications caused by mechanical ventilation, VAP is extremely unfavorable to the prognosis of patients with a mortality up to $60 \%$, which requires effective treatment measures to ensure the safety of patients [16-19]. Antibiotics, as a class of antiinfective drugs, are often used in the treatment of VAP, but their therapeutic effects are subject to many factors, and there are certain limitations in the treatment of VAP. Based on this, it is necessary to combine antibiotics with other therapeutic measures to improve the therapeutic effects for VAP patients. Nowadays, bronchoalveolar lavage with fiberoptic bronchoscope has been widely used in clinical practice, which can effectively suck out the respiratory secretions of patients for sputum culture, thus laying a theoretical foundation for the follow-up antibiotic treatment. In addition, acetylcysteine solution can fully liquefy the thick secretion, optimize the output rate of alveolar active substances in patients, and facilitate the discharge of sputum, which exhibits a positive auxiliary effect on the treatment of VAP patients.

CPIS is a comprehensive indicator used to judge the curative effect and prognosis of VAP patients, which possesses a high clinical guiding significance for the treatment of VAP patients. In this study, group A obtained lower CPIS scores than group $\mathrm{B}(P<0.001)$, which proved that patients in group $A$ given combined therapy garnered better curative effect and prognosis. Accordingly, the acetylcysteine solution combined with fiberoptic bronchoscopy alveolar lavage is effective in the treatment of VAP 
patients. After treatment, group A enjoyed better respiratory mechanics indexes than group $B$ $(P<0.001)$, which indicated a significantly reduced that pulmonary resistance of patients after the sputum was sucked out, a higher level of mechanical ventilation, and a markedly elevated pulmonary condition in group $\mathrm{A}$. In comparison with group $\mathrm{B}, \mathrm{PaO}_{2}$ and $\mathrm{PaO}_{2} / \mathrm{FiO}_{2}$ were strikingly higher but $\mathrm{PaCO}_{2}$ lower in group A than those in group B $(P<0.001)$, which indicated that acetylcysteine solution fully diluted the sputum in patients' lungs to facilitate the suction conducted by fiberoptic bronchoscope, thus substantially relieving the bronchial obstruction immediately. After treatment, group A yielded lower levels of inflammatory factors than group $\mathrm{B}(P<0.001)$, which was attributed to the fact that the secretion of patients was greatly diluted after combined treatment, and sensitive antibiotics played a corresponding role randomly, which weakened the inflammatory state of patients. In addition, patients in group A enjoyed a shorter antibiotic use time and a mechanical ventilation time than group $B(P<0.001)$, which indicated proved a promising result by the combined treatment. British scholar Lina Bale compared the clinical indexes of patients treated with conventional VAP and patients treated with acetylcysteine solution combined with bronchoalveolar lavage, and concluded that the level of inflammatory factors was lower in patients treated with combined therapy, with IL-8 of $(101.2 \pm 10.2) \mathrm{pg} / \mathrm{ml} / \mathrm{ml}$, CRP of $(37.2 \pm 6.1)$ $\mathrm{mg} / \mathrm{L} / \mathrm{L}$ and PCT of $(15.3 \pm 2.4) \mathrm{ng} / \mathrm{L} / \mathrm{L}$. This confirmed that combined therapy had positive significance for VAP treatment [20], which was consistent with the research results obtained in this paper.

\section{Limitations of the study}

The following limitations were identified in this study. It is a monocentric study with a small number of participants and short follow-up. A randomized controlled, multicenter, double-blind study with a large sample is needed to confirm the conclusion reached.

\section{CONCLUSION}

Acetylcysteine solution combined with fiberoptic bronchoscopy alveolar lavage is a reliable method to improve CPIS, respiratory mechanics indicators and blood gas levels in elderly patients with severe VAP; This strategy greatly reduces the level of inflammatory factors in patients; and shortens the relevant treatment time. Further investigations would help to establish a better solution for VAP patients.

\section{DECLARATIONS}

\section{Conflict of interest}

No conflict of interest is associated with this work.

\section{Contribution of authors}

This work was performed by all authors named in this article, and all liabilities pertaining to claims relating to the content of this article will be borne by all of them. The study was conceived and designed by Ju Guo. Ping Wang and Xiaoyu Ma collected and analyzed the data, Ju Guo wrote the manuscript. All authors read and approved the manuscript for publication.

\section{Open Access}

This is an Open Access article that uses a funding model which does not charge readers or their institutions for access and distributed under the terms of the Creative Commons Attribution License (http://creativecommons.org/licenses/by/ 4.0) and the Budapest Open Access Initiative (http://www.budapestopenaccessinitiative.org/rea d), which permit unrestricted use, distribution, and reproduction in any medium, provided the original work is properly credited.

\section{REFERENCES}

1. Arumugam SK, Mudali I, Strandvik G, El-Menyar A, AlHassani A, Al-Thani $H$. Risk factors for ventilatorassociated pneumonia in trauma patients: A descriptive analysis. World J Emerg Med 2018; 9: 203-210.

2. Spalding MC, Cripps MW, Minshall CT. VentilatorAssociated Pneumonia: New Definitions. Crit Care Clin 2017; 33: 277-292.

3. Shokri M, Ghasemian R, Bayani M, Maleh PA, Kamrani $M$, Sadeghi-Haddad-Zavareh M, Ebrahimpour S. Serum and alveolar procalcitonin had a weak diagnostic value for ventilator-associated pneumonia in patients with pulmonary infection score $\geq 6$. Rom J Intern Med 2018; 56: 9-14.

4. Kidd JM, Kuti JL, Nicolau DP. Novel pharmacotherapy for the treatment of hospital-acquired and ventilatorassociated pneumonia caused by resistant gramnegative bacteria. Expert Opin Pharmacother 2018; 19 : 397-408.

5. Wood GC, Jonap BL, Maish GO 3rd, Magnotti LJ, Swanson JM, Boucher BA, Croce MA, Fabian TC. Treatment of Achromobacter Ventilator-Associated Pneumonia in Critically III Trauma Patients. Ann Pharmacother 2018; 52: 120-125.

6. Fernando SM, Tran $A$, Cheng $W$, Klompas $M$, Kyeremanteng K, Mehta S, English SW, Muscedere J,

Trop J Pharm Res, May 2021; 20(5): 1065 
Cook DJ, Torres A, Ranzani OT, Fox-Robichaud AE, Alhazzani W, Munshi L, Guyatt GH, Rochwerg $B$. Diagnosis of ventilator-associated pneumonia in critically ill adult patients-a systematic review and metaanalysis. Intensive Care Med 2020; 46: 1170-1179.

7. Ly S, Magee WP. International Human Research and Ethics Standards: A Compilation of Legal Protections in Countries. Ann Glob Health 2017; 83: 3.

8. McLaughlin CW, Skabelund AJ, Easterling ER, Morris MJ. The Safety and Utility of Fiberoptic Bronchoscopy in the Very Elderly. J Bronchology Interv Pulmonol 2018; 25: 300-304.

9. Ranzani OT, Senussi $T$, Idone F, Ceccato A, Li Bassi G, Ferrer $M$, Torres A. Invasive and non-invasive diagnostic approaches for microbiological diagnosis of hospital-acquired pneumonia. Crit Care 2019; 23: 51.

10. Akhavan S, Hashemian SM. The role of electrical impedance tomography for monitoring during bronchoscopy: A case report. J Crit Care 2018; 48: 311313.

11. Souweine B, Veber B, Bedos JP, Gachot B, Dombret MC, Regnier $B$, Wolff $M$. Diagnostic accuracy of protected specimen brush and bronchoalveolar lavage in nosocomial pneumonia: impact of previous antimicrobial treatments. Crit Care Med 1998; 26: 236244.

12. Sharafkhah $M$, Abdolrazaghnejad $A$, Zarinfar $N$, Mohammadbeigi A, Massoudifar A, Abaszadeh $S$. Safety and efficacy of $\mathrm{N}$-acetyl-cysteine for prophylaxis of ventilator-associated pneumonia: a randomized, double blind, placebo-controlled clinical trial. Med Gas Res 2018; 8: 19-23.

13. Kókai $D$, Mosolygó T, Virók DP, Endrész V, Burián K. Nacetyl-cysteine increases the replication of Chlamydia pneumoniae and prolongs the clearance of the pathogen from mice. J Med Microbiol 2018; 67: 702708.

14. Blasi F, Page C, Rossolini GM, Pallecchi L, Matera MG, Rogliani $P$, Cazzola $M$. The effect of $\mathrm{N}$-acetylcysteine on biofilms: Implications for the treatment of respiratory tract infections. Respir Med 2016; 117: 190-197.

15. Letchford E, Bench S. Ventilator-associated pneumonia and suction: a review of the literature. Br J Nurs 2018; 27: 13-18.

16. Karad DD, Somani $Y$, Khande $H$, Yadav B, Kharat AS. Molecular characterization of a multidrugresistant/pandrug-resistant nosocomial polymicrobial infection with Klebsiella pneumoniae, Providencia rettgeri, and Acinetobacter baumannii from Rural Maharashtra, India. Acta Biochim Pol 2020; 67: 387392.

17. Cotoia A, Spadaro S, Gambetti G, Koulenti D, Cinnella G. Pathogenesis-Targeted Preventive Strategies for Multidrug Resistant Ventilator-Associated Pneumonia: A Narrative Review. Microorganisms 2020; 8: 821.

18. Mathai AS, Phillips A, Kaur $P$, Isaac R. Incidence and attributable costs of ventilator-associated pneumonia (VAP) in a tertiary-level intensive care unit (ICU) in northern India. J Infect Public Health 2015; 8: 127-135.

19. Peiffer-Smadja N, Bouadma L, Mathy V, Allouche K, Patrier J, Reboul M, Montravers P, Timsit JF, ArmandLefevre $L$. Performance and impact of a multiplex PCR in ICU patients with ventilator-associated pneumonia or ventilated hospital-acquired pneumonia. Crit Care 2020; 24: 366.

20. Qu D, Ren $X X$, Guo LY, Liang JX, Xu WJ, Han YH, Zhu $Y M$. Effect of $\mathrm{N}$-acetylcysteine inhalation on ventilatorassociated pneumonia caused by biofilm in endotracheal tubes. Zhonghua Er Ke Za Zhi 2016; 54: 278-282. 